\title{
Vibration based structural assessment of the rehabilitation intervention in r.c. segmental bridge
}

\author{
Paolo Franchetti ${ }^{1, \mathrm{a}}$, Michele Frizzarin ${ }^{1}$, Andrea Leonardi ${ }^{2}$ and Fabio Zeni ${ }^{2}$ \\ ${ }^{1}$ University of Padova, Department of Civil, Architectural and Environmental Engineering, Padova, Italy. \\ ${ }^{2}$ Vi.abilità Spa, Vicenza, Italy
}

\begin{abstract}
A vibration based structural assessment campaign was carried out on a r.c. segmental bridge in North East Italy. The bridge has a cantilever static scheme, fixed at the top of the piers and with a hinge at the centre of the span. The particular configuration of the hinge consists in a couple of steel elements, each one composed by a tongue and groove joint. Since the year 1960, the hinge was subjected to consumption and degradation, that caused a malfunctioning of the device. An intervention of rehabilitation of the bridge led to a reinforcement of the existing hinges with the coupling of new metallic devices: new tongue and groove hinges were applied, that by one side allow the horizontal displacements and rotation, by the other side strongly reduce the relative vertical displacements of the two parts of the bridge. A dynamic test campaign was set up in order to assess the effectiveness of the intervention. The principal dynamic parameters were calculated and analysed with respect to the intervention that was realized. The tests clearly showed the effectiveness of the intervention, and helped the designer to have a better understanding of the structural behaviour of the bridge.
\end{abstract}

\section{Introduction}

S. Agata bridge is a r.c. segmental bridge in North East Italy. The bridge is $180 \mathrm{~m}$ long, with a central span of $83 \mathrm{~m}$, and two piers with a height of $50 \mathrm{~m}$. The piers and the deck are composed by a box girder made by precast segments of post-tensioned reinforced concrete.

The bridge has a cantilever static scheme, fixed at the top of the piers and with a hinge at the centre of the span. The particular configuration of the hinge consists in a couple of steel elements, each one composed by a tongue and groove joint.

The bridge was built starting from its piers, founded in rock ground with shallow foundations. From the top of the piers, the segments were built one at a week at the two sides of the pier, correcting iteratively the deformations until the union of the two cantilevers.

Since the year 1960, when the bridge was built, during the huge amount of cycles of rotation and horizontal displacements, the hinge was subjected to consumption and degradation, which caused a malfunctioning of the device. In particular the transit of heavy trucks on the bridge was causing large oscillation and hammering between the two parts of the structures, with consequent structural damage.

The bridge represents a strategic structure since it is part of the only road that connects the towns across the valley. A damage of the bridge would cause not only a problem for the population of the valley, but also for the industrial activities present near the bridge.

\footnotetext{
${ }^{\mathrm{a}}$ Corresponding author: paolo.franchetti@unipd.it
}

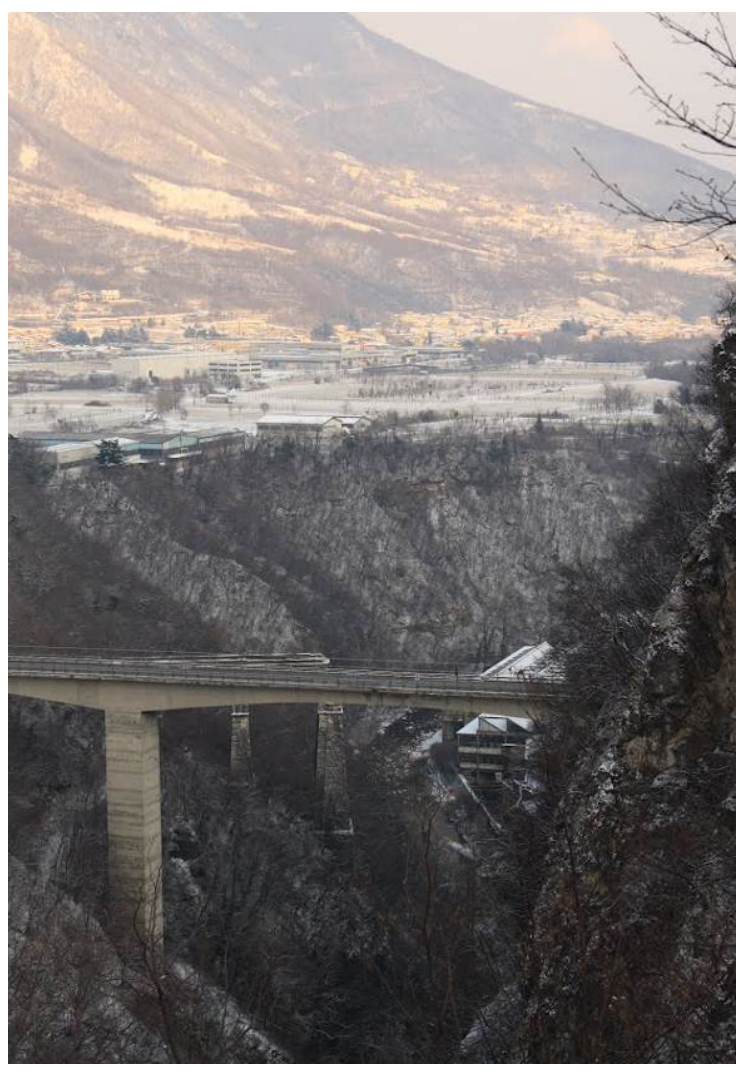

Figure 1. View of the bridge (Copyright by Luca Dalla Riva) 


\section{Description of the intervention}

An intervention of rehabilitation of the bridge was carried out. After the evaluation of several possibilities, it was decided to design an intervention that didn't affect the static scheme of the bridge. Moreover, it was decided not to add too much weight to the structure by building new hinges, avoiding also large demolitions of the existing devices. Finally, the main challenge that the manager of the bridge faced was to keep the bridge always open during the work.
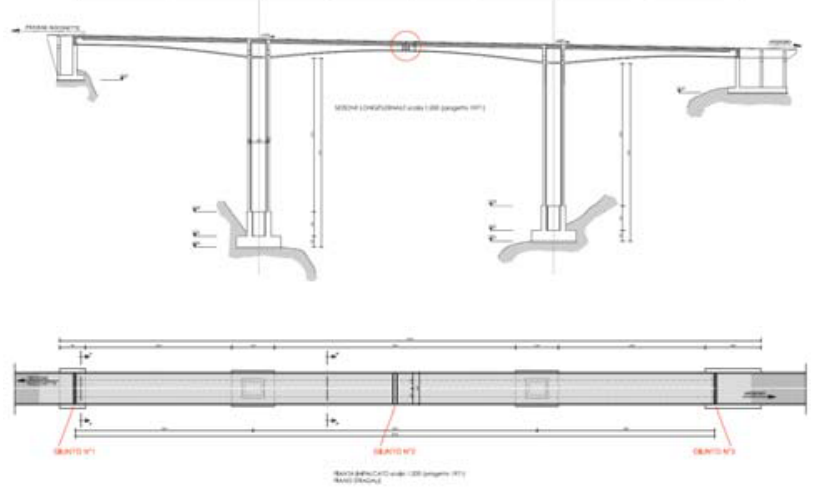

Figure 2. Scheme of the bridge

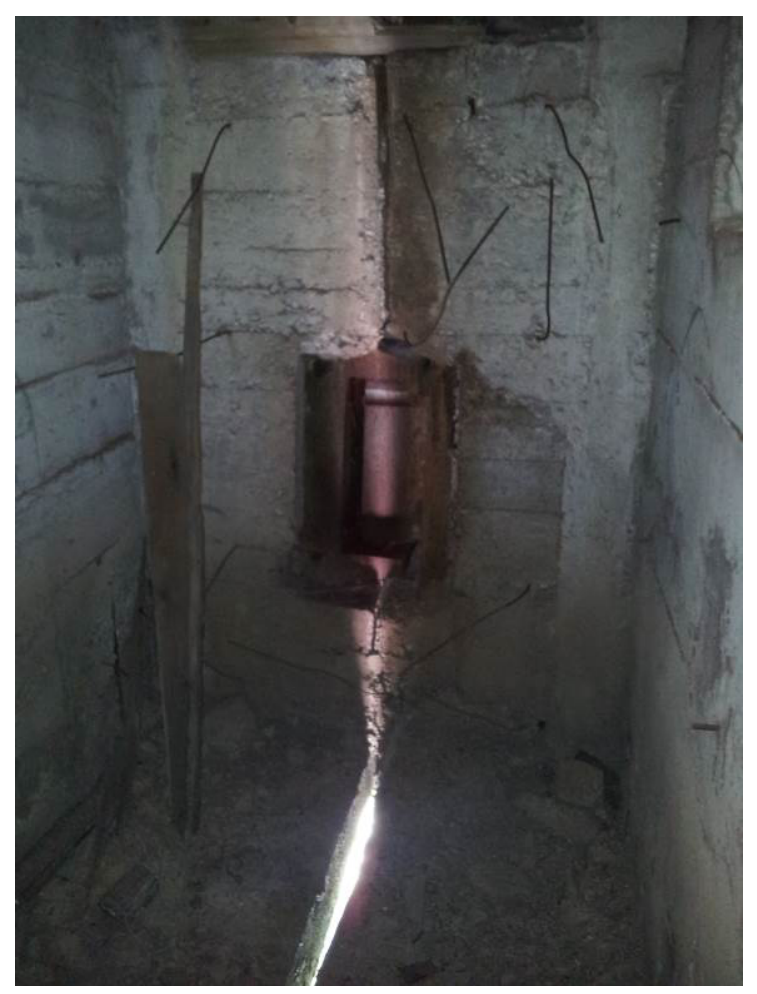

Figure 3. Tongue and Groove Joint at the middle of the deck

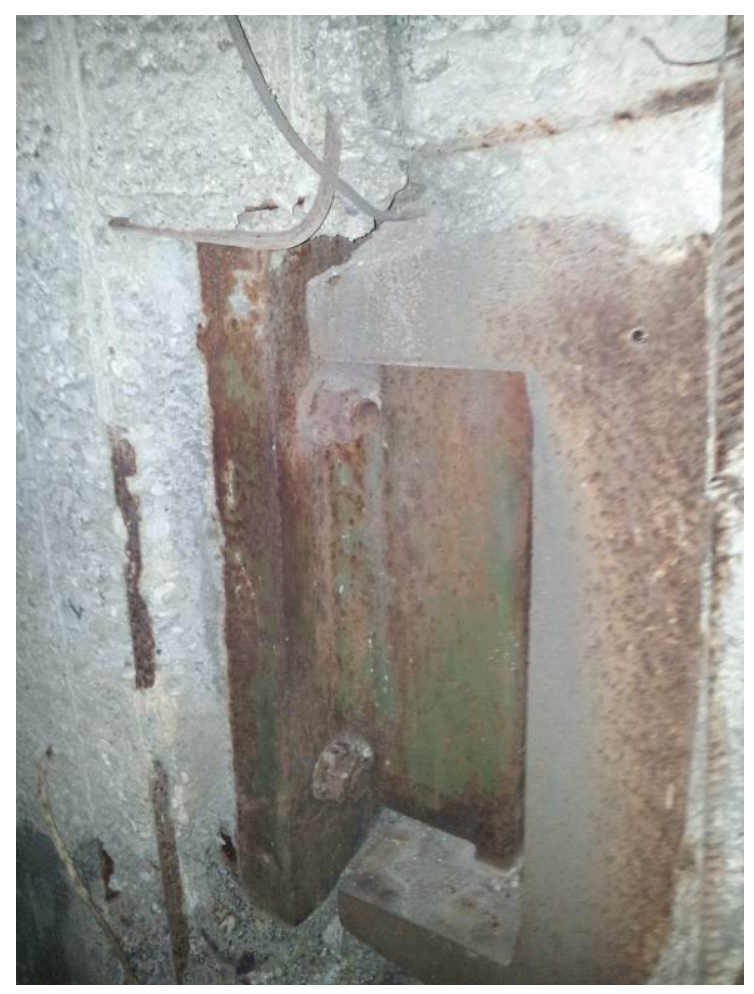

Figure 4. Tongue and Groove Joint at the middle of the deck detail

For these reasons the intervention led to a reinforcement of the existing hinges with the coupling of new metallic devices. The intervention was rapid and didn't involve large demolitions; new tongue and groove hinges were applied at the sides of the old hinges. The intervention allowed to maintain the traffic on the bridge always open, even though one direction at a time.

These new hinges had the purpose to avoid relative displacements between the two sides of the bridge, bringing the hinge to the original behaviour: transmitting only vertical solicitation (shear) without restraining bending moment (rotation) and axial deformation (for example due to temperature variation).

Together with the intervention on the hinges, the expansion joints were replaced by new steel joints. In the central joint it was necessary to rebuild a portion of concrete slab that was damaged by water infiltrations.

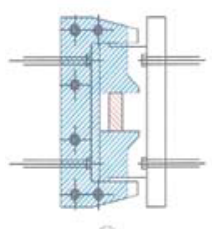

(1)

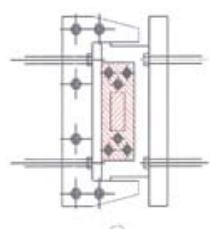

(2)

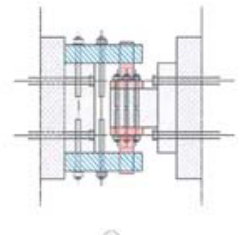

(3)
Figure 5. Scheme of the New Tongue and Groove Joint 


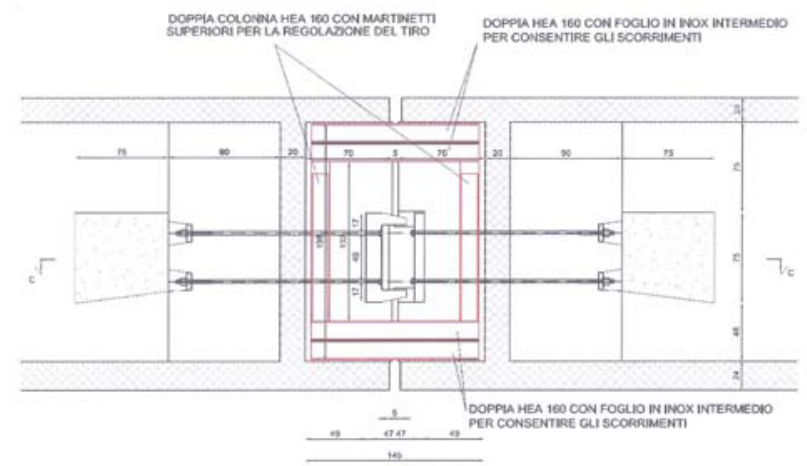

Figure 6. Scheme of the provisional reinforcement system for the installation of the New Tongue and Groove Joint

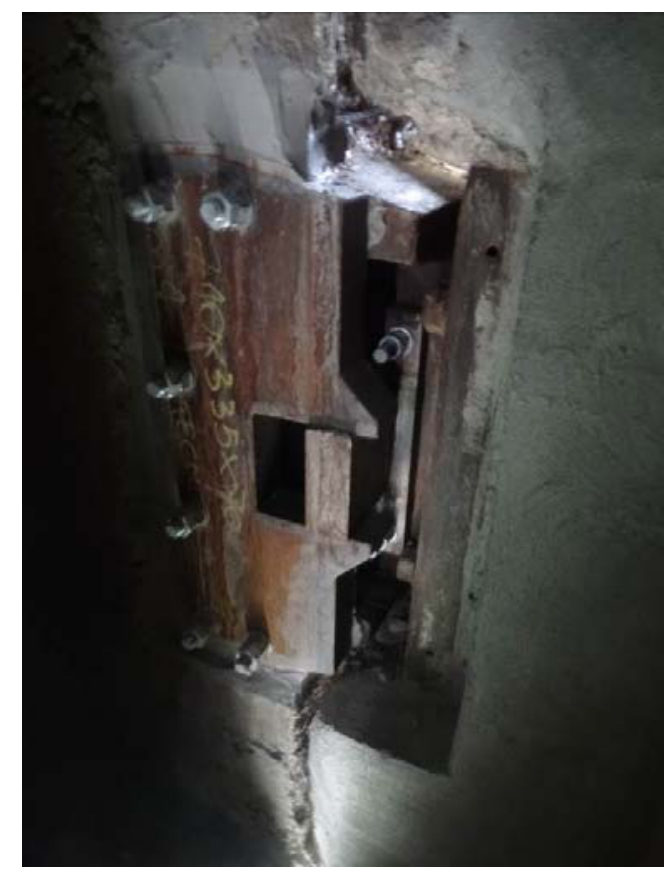

Figure 7. New Tongue and Groove Joint

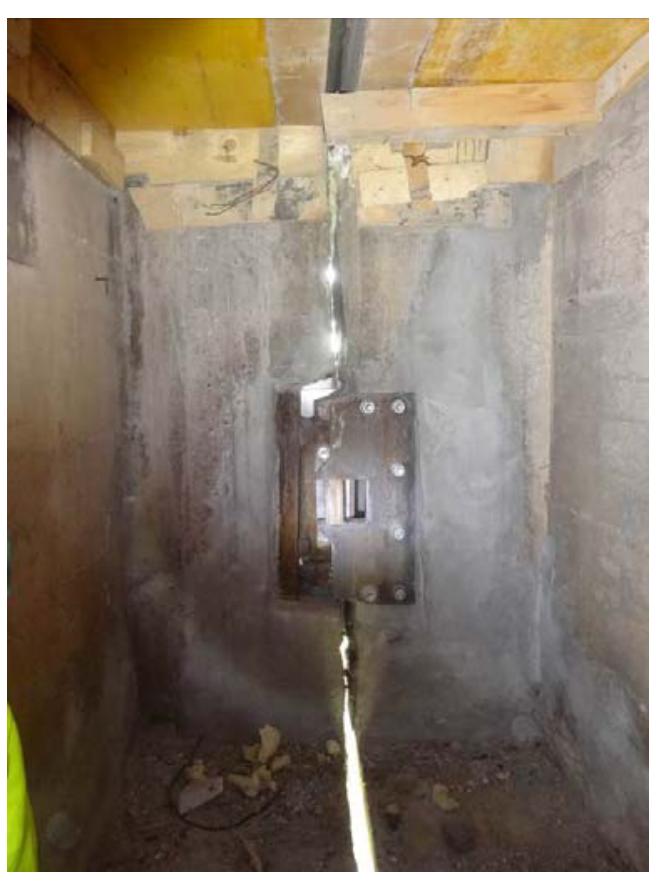

Figure 8. New Tongue and Groove Joint

\section{Dynamic test campaign}

A dynamic test campaign was set up in order to assess the effectiveness of the intervention.

Eight accelerometers were applied to the structure in order to identify most of the principal mode shapes of the structure.

Five accelerometers were applied to the structure, in order to identify at least a couple of vertical modes and the principal torsional mode. Moreover, two accelerometers were disposed in longitudinal direction, and one in transversal direction.

The excitation of the structure was applied through ambient vibration, mostly caused by the transit of vehicles and trucks.

In particular, some tests were made with the transit of a single truck, measuring also the damped vibration of the bridge after the transit.

Moreover, some tests were made with the total closure of the bridge for some minutes, in order to assess the effect of wind and other ambient excitations.

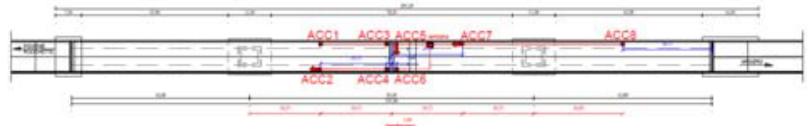

Figure 9. Sensor layout
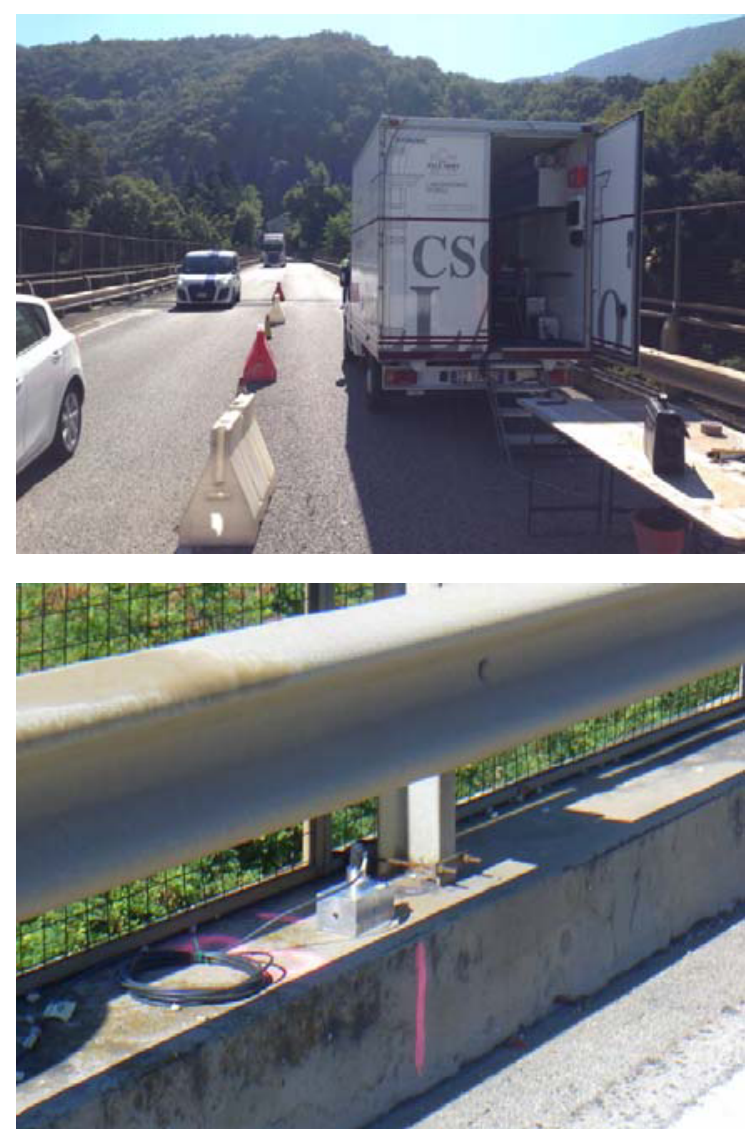

Figure 10. Execution of dynamic test 
The principal dynamic parameters were calculated and analysed, also with respect to the intervention that was realized.

In particular, the following were studied:

- The comparison between the measured natural frequencies and the theoretical FE model, helping the designer to have a better understanding of the structural behaviour of the bridge.

- The comparison between the vibrations at the two sides of the new hinge. The purpose was to test the effectiveness of the intervention, measuring if the hinges could transmit the shear from one side to the other without relative displacements.

\section{Results}

The principal results in terms of frequencies are showed below.

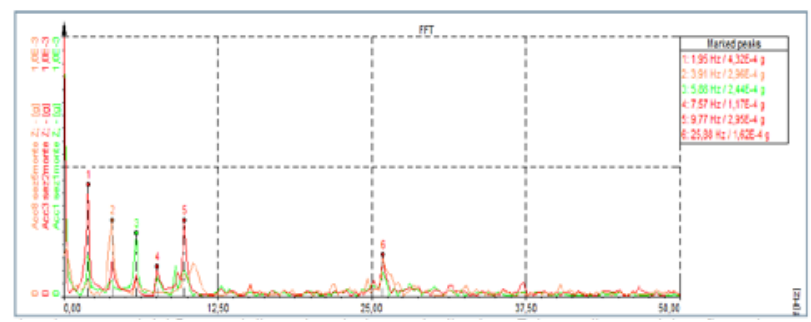

Figure 11. Principal vertical frequencies

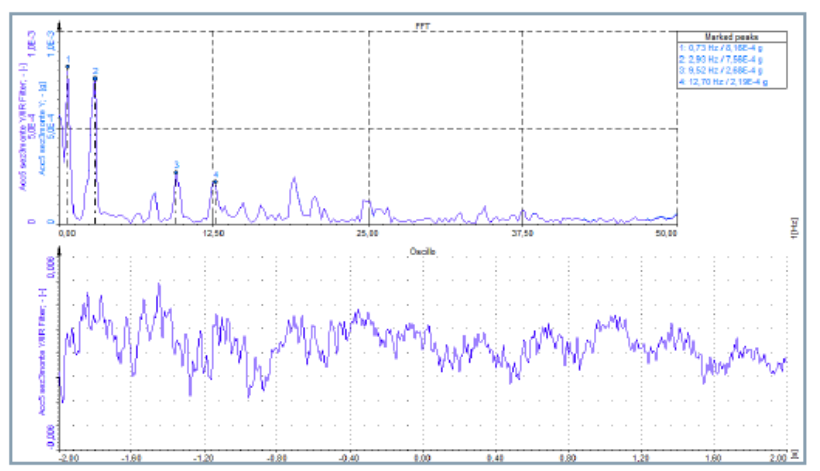

Figure 12. Principal transversal frequencies

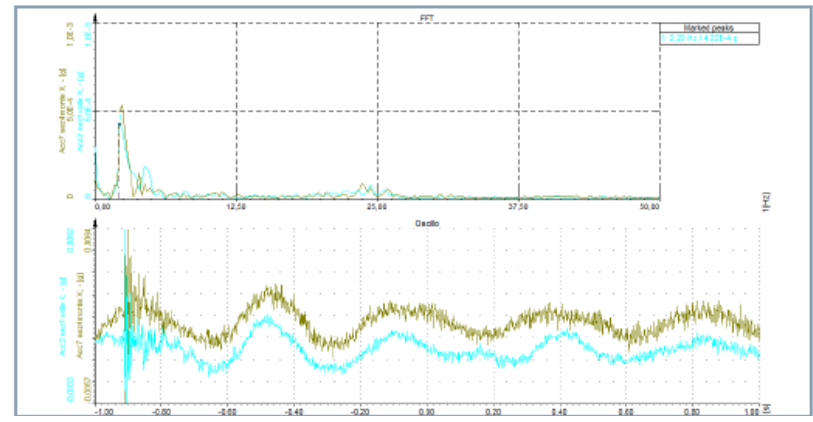

Figure 13. Principal longitudinal frequencies

The results were compared with the FE model built on the basis of the original project.

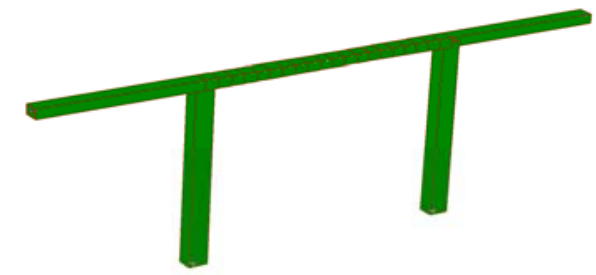

Figure 14. FE model
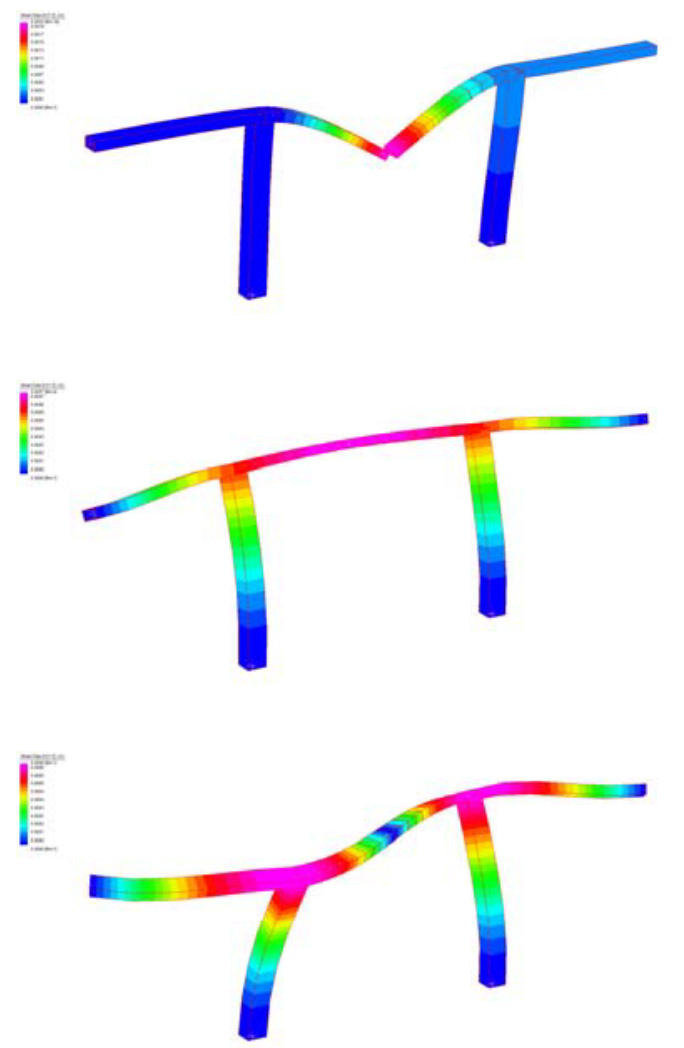

Figure 15. First mode shapes: vertical, transversal and torsional

Table 1. Comparison between experimental and theoretical mode shapes.

\begin{tabular}{|c|c|c|}
\hline Mode & $\begin{array}{c}\text { Experimental } \\
\text { frequency }(\mathbf{H z})\end{array}$ & $\begin{array}{c}\text { Theoretical } \\
\text { frequency } \mathbf{( H z )}\end{array}$ \\
\hline Transversal & 0.75 & 0.79 \\
\hline $1^{\text {st }}$ vertical & 1.95 & 1.75 \\
\hline $2^{\text {nd }}$ vertical & 3.95 & 4.27 \\
\hline Torsional & 9.75 & 8.0 \\
\hline
\end{tabular}

The FE model, after the model updating procedure, results in a good correspondence with the experimental values. The model updating procedure showed that the elastic modulus of the material is higher than standard concrete, with a general good behaviour of the whole structure. 
By comparing the time history response of the two sensors at the two sides of the bridge it was verified if the new hinges at the centre would create an effective shear connection between the two halves of the structure.
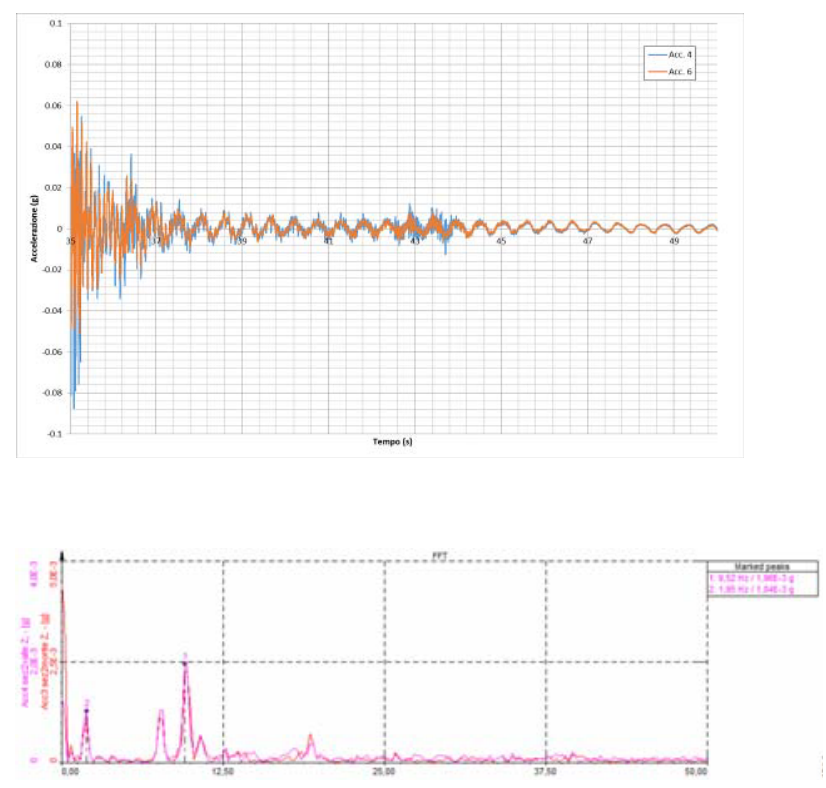

Figure 16. Comparison of the vibration of the sensors at the two sides of the hinge: time history and frequency.

The tests clearly showed the effectiveness of the intervention, and helped the designer to have a better understanding of the structural behaviour of the bridge.

\section{Conclusions}

A vibration based structural assessment campaign was carried out on a r.c. segmental bridge in North East Italy, after an intervention of rehabilitation that led to a reinforcement of the existing hinges with the coupling of new metallic devices. The principal dynamic parameters were calculated and analysed with respect to the intervention that was realized.

The tests clearly showed the effectiveness of the intervention, with a coupling of the behaviour of the two sensors at the sides of the hinge, without differential vibration frequencies.

Moreover, the procedure of model updating helped the designer to have a better understanding of the structural behaviour of the bridge.

\section{Acknowledgements}

The authors would like to acknowledge Vi-abilità Spa Fip Industriale and Contec Ingegneria.

\section{References}

1. Prietsley M. J. N., Seible F. and Calvi G. M., (1996), Seismic design and retrofit of bridges, John Wiley \& Sons, Inc., New York, U.S.
2. Modena, C. \& Reginato, F., with the cooperation of Stoppa M., Mesaroli M., Morbin A., Corsini A., 2003, Interventi di consolidamento, adeguamento statico e sismico ed allargamento del ponte sul fiume Adige a Zevio lungo la S.P. $\mathrm{n}^{\circ} 20$ "dell'Adige e del Tartaro": progetto esecutivo - Relazione generale, Verona, 16 December 2003.

3. Modena, C., Castegini, R., De Zuccato, L. \& Stoppa, M. 2004. Interventi di adeguamento e miglioramento sismico: l'esempio del ponte di Albaredo d'Adige in Provincia di Verona, Proc. Giornate AICAP 2004, Verona, 26-29 May 2004.

4. Bulletin d'information n. 243, CEB-FIP, Strategies for Testing and Assessment of Concrete Structures, Guidance Report, Lausanne, May 1998. 